\title{
Effect of intimal flap motion on flow in acute type $B$ aortic dissection by using fluid-structure interaction
}

\author{
Mei Yan Chong, ${ }^{1,2}$, Boram Gu${ }^{2}$, Bee Ting Chan ${ }^{3}$ Zhi Chao Ong ${ }^{4}$, Xiao Yun $\mathrm{Xu}^{2}$, and Einly Lim ${ }^{1}$ \\ ${ }^{1}$ Department of Biomedical Engineering, University of Malaya, Malaysia. \\ ${ }^{2}$ Department of Chemical Engineering, Imperial College London, United Kingdom. \\ ${ }^{3}$ Department of Mechanical, Materials and Manufacturing Engineering, University of Nottingham, Malaysia. \\ ${ }^{4}$ Department of Mechanical Engineering, University of Malaya, Malaysia.
}

\begin{abstract}
A monolithic, fully coupled fluid-structure interaction (FSI) computational framework was developed to account for dissection flap motion in acute type B aortic dissection (TBAD). Analysis of results included wall deformation, pressure, flow, wall shear stress (WSS), von. Mises stress and comparison of hemodynamics between rigid wall and FSI models. Our FSI model mimicked realistic wall deformation that resulted in maximum compression of the distal true lumen (TL) by $21.4 \%$. The substantial movement of intimal flap mostly affected flow conditions in the false lumen (FL). Flap motion facilitated more flow entering the FL at peak systole, with the TL to FL flow split changing from 88:12 in the rigid model to 83:17 in the FSI model. There was more disturbed flow in the FL during systole (5.8\% FSI vs. 5.2\% rigid) and diastole (13.5\% FSI vs. 9.8\% rigid), via a $\lambda_{2}$-criterion. The flap-induced disturbed flow near the tears in the FSI model caused an increase of local WSS by up to $70 \%$ during diastole. This resulted in a significant reduction in the size of low time-averaged WSS (TAWSS) regions in the FL (113.11 $\mathrm{cm}^{2}$ FSI vs. $177.44 \mathrm{~cm}^{2}$ rigid). Moreover, the FSI model predicted lower systolic pressure, higher diastolic pressure, and hence lower pulse pressure. Our results provided new insights into the possible impact of flap motion on flow in aortic dissections, which are particularly important when evaluating hemodynamics of acute TBAD.
\end{abstract}

\section{Keywords:}

Aortic dissection (AD), fluid-structure interaction (FSI), computational fluid dynamics (CFD), intimal flap motion, wall elasticity 


\subsection{Introduction}

During the acute phase of type B aortic dissection (TBAD), the first two weeks since symptom onset, the initial tear in the aortic intima allows pulsating blood to enter the media, splitting the medial layer along the length of the aorta, into true lumen (TL) and false lumen (FL). The tissue that separates the FL from the TL is known as the intimal flap. The stress produced within the aorta may give rise to additional tears in the flap, which may initiate further dissections. Acute dissection can result in a thin, inflamed, extremely fragile outer aortic wall and a highly mobile, curvy flap [1]. The flap is sensitive to changes in hemodynamic pressures within the aorta, often contributing to dynamic stenosis or static occlusion of branch arteries, impairing blood flow to branch arteries [2]. Hence, the acute phase has a high risk of lifethreatening complications.

The natural course of TBAD can be either early complications or chronic events. Acute complicated TBAD has early complications evidenced by hemodynamic instability, peripheral vascular ischaemia or malperfusion syndrome. Thoracic endovascular aortic repair (TEVAR) has evolved as an alternative therapeutic option to re-establish normal blood flow by covering the proximal entry tear and stimulating aortic remodelling. On the other hand, acute uncomplicated TBAD is preferentially treated medically, and thus naturally transitions into the chronic state. Although the aortic wall partially heals and therefore becomes less fragile due to fibrosis while the flap thickens, straightens and becomes less mobile [1], the outer aortic wall remains weakened and prone to gradual dilatation and aneurysm formation. Hence, patient follow-ups continue to show a high number of late complications, despite best medical treatments [3].

Loss of aortic elasticity is accepted as an independent predictor of adverse cardiovascular outcomes at an early stage [4], potentially affecting the feasibility and success of TEVAR [5], as well as contributing to long-term poor medical treatment outcome [6]. Computational fluid dynamics (CFD) is a promising modelling technique to assist the clinical management of TBAD by providing insight into the complex hemodynamics of TBAD. However, most CFD studies reported so far are based on rigid wall simulations, assuming wall motion has a minor effect on the hemodynamics [7-9]. There were simplified methods to account for wall compliance in a less computationally expensive manner, such as lumpedparameter models in rigid-wall simulations as proposed by Rudenick et. al. (2015) who modelled the TL and FL as an individual compartment using L-type network, which comprises 
of local resistance to flow, compliance of the lumen and intraluminal inertial properties of flow [10], and Bonfanti et. al. (2019) who introduced a capacitor before the inlet of the aorta [11]. The inclusion of the outer wall elasticity altered flow and pressure predictions, but their models did not take the drastic movement of the flap into account, and thus were unable to study the effect of flap movement on hemodynamics, or to predict the deformation and wall stress in the dissected aorta. Apart from aortic wall compliance, there is evidence showing that the intimal flap could oscillate substantially in a pattern correlated with the difference between the true and false lumen pressure [12-14], thereby necessitating the use of more advanced fluidstructure interaction (FSI) modelling approaches to allow for dynamic interactions between blood flow and wall motion.

In recent years, FSI simulations of aortic dissection have been reported. Chen et. al. (2016) examined the effect of flap movement on flow in an idealised dissection model and validated their computation results against bench experiments using healthy porcine aorta [15]. The idealised dissection model however corresponded to porcine aorta with a small diameter and limited flap length, making it difficult to study the impact of tears on the hemodynamics of dissection. The geometrical limitations were then addressed using a patient-specific geometry reconstructed from magnetic resonance imaging (MRI) and computed tomography (CT) data to account for more clinically relevant settings [16, 17]. Alimohammadi et. al. (2015) compared FSI and rigid wall models and found that there was a large difference in predicted time-averaged wall shear stress (TAWSS) and collocated oscillatory shear index (OSI) in the proximal and distal FL [16]; high OSI and low TAWSS can be indicative of increased risk of rupture, calcification and wall thickening. Qiao et. al. (2019) also investigated TAWSS and OSI using coupled FSI with two-phase non-Newtonian blood model and showed that while TAWSS was not significantly affected by the rigid wall assumption, FSI simulation was needed to better quantify OSI [17]. In addition, there was low shear stress, high OSI, along with flow reversal and low red blood cells distribution in the proximal FL. The inhomogeneous blood cells concentration in the recirculation zone could trigger atherosclerosis plaque build-up [18], potentially leading to atherosclerosis in the proximal FL during the late stage of dissection development.

The aforementioned FSI simulations of TBAD were solved using a partitioned approach with limited wall deformation of less than $1 \mathrm{~mm}$ [15-17] owing to convergence and stability issues. The flap movement has been investigated using phase contrast-MRI [14] and 
ECG-gated CT $[12,13]$, and assessed in terms of TL and FL diameter changes in a cardiac cycle. Although flap dynamic behaviours were highly variable for each patient, the instantaneous flap movement, especially at peak systole, can reach up to $10.2 \mathrm{~mm}$ in the acute phase [13]. Drastic flap fluctuations under pulsatile flow were also demonstrated by previous experimental work on a compliant flow phantom of the aorta with a mobile intimal flap [19] and one-way FSI simulation for acute and chronic TBAD [20]. These findings suggest that the assumption of constrained wall deformation of $<1 \mathrm{~mm}$ in the existing FSI studies of aortic dissection needs to be relaxed for a more realistic and accurate prediction of hemodynamics. Also, an alternative approach is required to resolve the instability issues encountered in standard partitioned FSI solvers [21]. Monolithic FSI solvers that integrate the flow and structural equations simultaneously, appear to be a promising solution by overcoming the aforementioned problems [21-23]. The monolithic approach has also been demonstrated to produce better convergence behaviour with lower computational time than the partitioned approach for FSI simulations involving large deformation [24]. A recent study by Baumler et. al. (2020) [23] applied the monolithic FSI approach using an open source code, SimVascular, in a patient specific TBAD model. A good agreement with 4D PC-MRI was obtained by applying pre-stress, viscoelastic tissue support and a regionally defined flap elasticity, yet at the expense of significantly high computational cost.

In this study, we present a monolithic, fully coupled FSI computational framework to account for wall compliance, particularly the intimal flap motion and its effect on hemodynamics of TBAD in comparison with a rigid-wall simulation using an idealised model relevant to acute dissection. This is an extension of a previous study [20] which focused on estimating the mechanical properties of the intimal flap and its dynamic motion under pulsatile flow. Flap motion of up to $4.6 \mathrm{~mm}$ is examined in the present study, and the influence of flap motion on flow has been quantitatively analysed in terms of TL and FL flow splits, disturbed flow in the FL, luminal pressure difference, wave propagation and time-averaged WSS indices. 


\subsection{Methods}

\subsection{Idealised model geometry}

A computational 3D model of type B aortic dissection was constructed using Solid Works 2018 (Dassault Systems, Velizy, France). The geometric features of the model were selected based on anatomical measurements (Figure $1 \&$ Table 1), mimicking a dissected human aorta at acute phase $[25,26]$. Based on CT scans of acute dissections, the larger lumen is usually the FL $[25,27]$, with the TL and FL covering approximately $45 \%$ and $53 \%$ of the descending aorta respectively, and the flap is most commonly curved towards the FL [27]. The proximal and distal tear locations were measured from the left subclavian artery (LSA) [28]. A tear size of $10 \mathrm{~mm}$ was chosen, as this is the optimal cut-off value for prediction of aortic complications during follow-up [29]. The fluid and structural domains are defined in Figure $1 \mathrm{a}-\mathrm{b}$, where a uniform wall thickness of $1.6 \mathrm{~mm}$ [30] and a flap thickness of $0.8 \mathrm{~mm}$ [26] were prescribed. As the motion of the descending thoracic aorta is constrained by the presence of intercostal arteries, five pairs of intercostal arteries were included [31].

\subsection{Fluid domain}

Blood flow is governed by the incompressible Naiver-Stokes and continuity equations in a moving domain described by an arbitrary Lagrangian-Eulerian (ALE) frame of reference, which can be written as

$$
\begin{aligned}
& \rho_{\text {fluid }} \frac{\partial \mathbf{u}_{\text {fluid }}}{\partial \mathrm{t}}+\rho_{\text {fluid }}\left(\mathbf{u}_{\text {fluid }} \cdot \nabla\right) \mathbf{u}_{\text {fluid }}=\nabla \cdot \boldsymbol{\sigma}_{\text {fluid }}+\mathbf{F} \\
& \rho_{\text {fluid }} \nabla \cdot \mathbf{u}_{\text {fluid }}=0 \\
& \text { where } \boldsymbol{\sigma}_{\text {fluid }}=\left[-p \mathbf{I}+\mu_{\text {fluid }}\left(\nabla \mathbf{u}_{\text {fluid }}+\left(\nabla \mathbf{u}_{\text {fluid }}\right)^{\mathbf{T}}\right)\right]
\end{aligned}
$$

where $\mathbf{u}$ is velocity in $\mathrm{m} / \mathrm{s}, \mathrm{p}$ is pressure in $\mathrm{kg} /\left(\mathrm{m} . \mathrm{s}^{2}\right), \rho_{\text {fluid }}$ is fluid density in $\mathrm{kg} / \mathrm{m}^{3}, \mu$ is dynamic viscosity in $\mathrm{kg} /(\mathrm{m} . \mathrm{s}), \mathbf{F}$ is the body force in $(\mathrm{kg} . \mathrm{m}) / \mathrm{s}^{2}, \boldsymbol{\sigma}_{\text {fluid }}$ is stress tensor in $\mathrm{kg} /\left(\mathrm{m} . \mathrm{s}^{2}\right)$, I is isotropic second-order tensor, $\nabla$ is gradient operator and ${ }^{\mathbf{T}}$ is transpose tensor. The subscript fluid denotes the variables and properties in the fluid domain. Blood was modelled as a nonNewtonian fluid using the Quemada viscosity $\mu_{\text {fluid }}$ [32] model, with a fluid density $\rho_{\text {fluid }}=$ $1060 \mathrm{~kg} / \mathrm{m}^{3}$. Among various non-Newtonian viscosity models, the Quemada model [32] is a 
reliable multi-phase fluid model that considers all important factors affecting blood viscosity: shear rate, plasma viscosity, haematocrit and red cell aggregation/deformation.

$\mu=\mu_{p}\left(1-\frac{1}{2} \frac{k_{0}+k_{\infty}}{1+\sqrt{\dot{\gamma} / \gamma_{c}}} H_{t}\right)^{-2}$

where $\mu$ is the blood viscosity, $\mu_{p}$ is the plasma viscosity, $k_{0}$ is the maximum volume fraction for zero shear rate, $k_{\infty}$ is the maximum volume fraction for infinite shear rate, $\dot{\gamma}$ is the shear rate, $\gamma_{c}$ is the characteristic rate of rouleaux formation/ degradation and $H_{t}$ is the haematocrit. The values of the model parameters are $\mu_{p}=1.2 \times 10^{-3}$ Pa.s, $k_{0}=4.01, k_{\infty}=1.77, \gamma_{c}=$ $4.2 s^{-1}, H_{t}=0.45[33]$.

Time-dependent pulsatile flow waveform with a mean flow of $3.87 \mathrm{~L} / \mathrm{min}$ was applied at the model inlet (Figure 2) [34], while pressure waveform calculated through a three-element Windkessel model was adopted at the model outlet. The Windkessel parameters $C$ (compliance), $R_{P}$ (peripheral resistance) and $R_{C}$ (characteristic impedance) were estimated using the methodology presented in [35], along with the given inflow waveform and the mean TL pressure measurements reported in the literature [36]. Further details on the tuning procedure of the Windkessel parameters and their values can be found in the Supplementary Materials. A critical Reynolds number can be used to assess the flow regime for pulsatile flow [37]: $\operatorname{Re}_{\mathrm{c}}=\mathrm{k} \alpha$, where $\operatorname{Re}_{\mathrm{c}}$ is the critical Reynolds number, $\mathrm{k}$ is the constant of proportionality ranging from 250 to 1000 and $\alpha$ is the Womersley number. Reynolds number and Womersley number are defined as follows in Eqs. (4) and (5) respectively.

$$
\begin{gathered}
R e=\frac{\rho_{\text {fluid }} D u_{\text {inlet }}}{\mu_{\text {fluid }}} \\
\alpha=\frac{D}{2} \sqrt{\frac{\omega \rho_{\text {fluid }}}{\mu_{\text {fluid }}}}
\end{gathered}
$$

where Re is the Reynolds number, $\alpha$ is the Womersley number, $\mathrm{D}$ is the inlet diameter of the aorta in $\mathrm{m}, u_{\text {inlet }}$ is the inlet velocity of the fluid in $\mathrm{m} / \mathrm{s}$ and $\omega$ is the angular frequency of the pulsatile flow in $\mathrm{s}^{-1}$. In our model, the mean Womersley number was 30 , hence $\operatorname{Re}_{\mathrm{c}}$ would be in the range from 7506 to 30025 . The mean and maximum Reynolds number was 576 and 3464 
respectively, which was below the threshold for turbulent flow, thus blood flow was treated as laminar [37].

\subsection{Structural domain}

The structural domain is governed by the momentum-balance equations, shown in Eq. (6).

$\rho_{\text {solid }} \frac{\partial^{2} \boldsymbol{u}_{\text {solid }}}{\partial t^{2}}-\nabla \cdot \boldsymbol{\sigma}_{\text {solid }}=\boldsymbol{F}$

where $\boldsymbol{F}=\boldsymbol{I}+\nabla \boldsymbol{u}_{\text {solid }}$

where $\mathbf{u}_{\text {solid }}$ is displacement in $\mathrm{m}, \rho_{\text {solid }}$ is wall density in $\mathrm{kg} / \mathrm{m}^{3}, \boldsymbol{\sigma}_{\text {solid }}$ is first Piola-Kirchhoff stress tensor, $\boldsymbol{F}$ is deformation gradient tensor, $\mathbf{I}$ is the isotropic second-order tensor and $\nabla$ is the gradient operator. The subscript solid denotes the variables and properties in the structural domain.

The aortic wall and intimal flap were treated as isotropic, homogenous and linearly elastic materials. Hence, the stress-strain relationship followed Hooke's law, Eq. (7).

$\boldsymbol{S}-\boldsymbol{S}_{0}=\bar{C}\left(\varepsilon-\varepsilon_{0}-\varepsilon_{\text {inel }}\right)$

where $\mathbf{S}$ is second Piola-Kirchhoff stress tensor, $\bar{C}=C(E, v)$ is material's stiffness matrix in a function of Young's modulus E and Poisson ratio v, and $\varepsilon$ is strain calculated using Eq. (8).

$\varepsilon=\frac{1}{2}\left[\left(\nabla \boldsymbol{u}_{\text {solid }}\right)^{T}+\nabla \boldsymbol{u}_{\text {solid }}+\left(\nabla \boldsymbol{u}_{\text {solid }}\right)^{T} \nabla \boldsymbol{u}_{\text {solid }}\right]$

where $\mathbf{u}_{\text {solid }}$ is displacement in $\mathbf{m}$ and ${ }^{\mathbf{T}}$ is transpose tensor.

The aortic wall had a Young's modulus of $2.7 \mathrm{MPa}$ [38, 39], while the flap-to-wall Young modulus ratio (R) was 2.50 [20] (Table 2). The two ends of the aorta and branches of intercostal arteries were held as fixed constraints [31], where $\boldsymbol{u}_{\text {solid }}=0$, to mimic tethering of the aorta by the surrounding connective tissues and the vertebral and other collateral arteries. 


\subsection{Mesh generation and fluid-structure coupling}

Both fluid and wall volumes were discretised into tetrahedral elements using in-built meshing tools available in COMSOL Multiphysics® (v5.2, COMSOL AB, Sweden), with eight prismatic layers in the fluid domain near the wall. Mesh sensitivity tests for the coupled domains were performed with transient boundary conditions initialised with $0 \mathrm{~Pa}$ for threeelement Windkessel model (details of the mesh are given in Table 3). Results for pressure, velocity, wall shear stress, displacement and von. Mises stress at peak systole were monitored. Solutions were considered mesh independent when the monitored parameters differed by less than 3\% between two successively refined meshes (Table $4 \&$ Table 5). Winslow mesh smoothing was utilised to ensure adequate mesh quality for FSI problems with large deformation. The approach consists of mapping mesh in the computational space coordinates $(\xi, \eta, \zeta)$ onto an arbitrary domain in physical space coordinates $(\mathrm{x}, \mathrm{y}, \mathrm{z})$. Winslow equations [40, 41] allow the mesh nodes to be moved and smoothed to conform to a moving surface, while maintaining good mesh element quality during the mesh update (Figure 3). Remeshing of the computational domains were therefore not necessary. The degree of freedom for the linear system to be solved for rigid-wall and FSI models were 222,909 and 525,428 respectively. The selected mesh gave a reasonable accuracy with the available computational power and acceptable simulation time. At the fluid-solid interfaces, no-slip condition and traction equilibrium were enforced, represented by Eqs. (9) and (10) respectively.

$$
\begin{aligned}
& \overline{\boldsymbol{u}_{\text {fluıd }}}=\frac{\partial \overline{\boldsymbol{u}_{\text {solıd }}}}{\partial \mathrm{t}} \\
& \overline{\boldsymbol{\sigma}_{\text {fluıd }}} \cdot \boldsymbol{n}=\overline{\boldsymbol{\sigma}_{\text {solıd }}} \cdot \boldsymbol{n}
\end{aligned}
$$

where $\boldsymbol{u}$ is fluid velocity in $\mathrm{m} / \mathrm{s}, \boldsymbol{u}_{\text {solid }}$ is displacement in $\mathrm{m}, \boldsymbol{\sigma}_{\text {fluid }}$ is stress tensor in $\mathrm{kg} /\left(\mathrm{m} . \mathrm{s}^{2}\right)$, $\boldsymbol{\sigma}_{\text {solid }}$ is first Piola-Kirchhoff stress tensor, $\mathbf{n}$ is unit normal vector to the surface and the macron mark $\left(^{-}\right)$denoted that the values were defined on the fluid-solid interfaces only.

Fluid and structural domains were solved simultaneously with the finite-element commercial solver COMSOL Multiphysics® (v5.2, COMSOL AB, Sweden). A MUMPS direct solver was used to solve linear systems based on LU factorisation on the matrix [42]. The fluid velocity and pressure were discretised using first-order Lagrange shape function and stabilised using streamline and crosswind diffusions, while the structural displacement was solved via quadratic discretisation. A strict backward differentiation formula (BDF) timestep of $5 \mathrm{~ms}$ was found to be sufficient for numerical accuracy. To ensure periodicity, each 
simulation was run for fourteen cycles and the average simulation time was three hours per cycle for the rigid model and 33 hours per cycle for the FSI model on a workstation Intel Core i7-2600 CPU @ 3.40GHz, 32 GB RAM. All results presented were taken from the last cycle, after a periodic solution was reached.

\subsection{Identification and quantification of disturbed flow in FL}

The flow disturbances, also known as vortices, formed when blood passes through the lumina. The vortical regions in the FL were detected using a $\lambda_{2}$-criterion for an incompressible flow using Eq. 11 [43, 44] and visualised as isosurfaces throughout a cardiac cycle [45]. A threshold of $\lambda_{2}<\lambda_{\text {threshold }}$ was applied to identify the significant vortical region [43]. The same $\lambda_{\text {threshold }}\left(-10 \mathrm{~s}^{-2}\right)$ was used in both FSI and rigid models for comparison.

$\lambda_{2}=\frac{\partial v_{x}}{\partial \mathrm{y}} \frac{\partial v_{y}}{\partial \mathrm{x}}+\left(\frac{\partial v_{y}}{\partial \mathrm{y}}\right)^{2}+\frac{\partial v_{y}}{\partial \mathrm{z}} \frac{\partial v_{z}}{\partial \mathrm{y}}$

where $\lambda_{2}$ is second eigenvalue of the tensor $\mathbf{S}^{2}+\mathbf{\Omega}^{2}, \mathbf{S}$ and $\boldsymbol{\Omega}$ are the symmetric and antisymmetric parts of the velocity gradient tensor and $\boldsymbol{v}_{\boldsymbol{x}}, \boldsymbol{v}_{\boldsymbol{y}}, \boldsymbol{v}_{\boldsymbol{z}}$ are the velocity field in respective $\mathrm{x}, \mathrm{y}, \mathrm{z}$ components in $\mathrm{m} / \mathrm{s}$.

In quantitative assessment, the flow disturbance zones were measured as the total volume of vortices in the FL. To have a fair comparison between the rigid (constant FL volume) and FSI models (FL volume was changing), the percentage of disturbed flow in the FL was calculated using Eq. (12).

Percentage of disturbed flow $=\frac{\text { Total volume of vortices in FL }\left(\mathrm{cm}^{3}\right)}{\text { Instantaneous FL volume }\left(\mathrm{cm}^{3}\right)} \times 100 \%$ 


\subsection{Results}

\subsection{Displacement}

The mobility of the flap, represented by the temporal variation of flap displacement (Figure 4), and its range and mean values (Table 6), was much higher than the aortic wall. This was due to the thinner and more compliant flap in acute dissection, compared to the relatively thicker aortic wall.

The flap moved back and forth between the TL and FL in response to changes in fluid pressure (Figure 5). The direction of blood flow influenced the flap motion. At peak systole (t $=0.16 \mathrm{~s}$ ), blood entered the FL through the proximal tear, and left the FL from the distal tear. The proximal flap curved towards the FL, while the distal flap curved towards the TL to a greater extent, due to higher FL pressure. As diastole continued (up to $t=0.41 \mathrm{~s}$ ), the configuration of flap changed when most of the FL flow was reversed and re-directed to the TL through the proximal tear. Hence, the proximal flap curved towards the TL, while the distal flap slightly curved towards the FL.

\subsection{Flow and pressure}

The instantaneous velocity streamlines shown in Figure 6 revealed that flap movement caused more disturbed flow in the FSI model compared to the rigid model. During systole, higher pressure in the distal FL pushed the flap towards the TL (Figure 9), resulting in reduction of the TL cross-sectional area. TL flow was partly obstructed with lower mean systolic velocity of $0.29 \mathrm{~m} / \mathrm{s}$. For the rigid model, the TL flow pattern was relatively uniform with mean systolic velocity of $0.41 \mathrm{~m} / \mathrm{s}$. The disturbed flow regions were identified through $\lambda_{2}$ criterion using Eq. 14 (Figure 7). $\lambda_{2}$ is superimposed onto instantaneous velocity streamlines, where regions of flow disturbance had high $\lambda_{2}$ values. These regions were mostly adjacent to the proximal and distal tears. In the presence of flap movement, there were more vortices regions in the FL throughout a cardiac cycle; the volume of vortices increased from $13.1 \mathrm{~cm}^{3}$ with the rigid model to $14.8 \mathrm{~cm}^{3}$ during systole. The vortices in the middle of the FL were a consequence of flap motion-induced secondary flow, which continued to grow during diastole $\left(34.9 \mathrm{~cm}^{3}\right.$ FSI vs. $25.0 \mathrm{~cm}^{3}$ rigid), indicating more flow reversal in the FL.

Wave propagation was another interesting comparison between the FSI and rigid models. In Figure 8 and Figure 9, flow waveforms obtained across the tears, and pressure difference waveforms obtained in proximal and distal locations, respectively, were shown and 
compared. The pressure difference is defined as the difference of the spatially averaged TL and FL pressures over their respective cross-sectional areas, i.e., $\Delta \mathrm{P}=\mathrm{P}_{\mathrm{TL}}-\mathrm{P}_{\mathrm{FL}}$. There was a time delay of $0.07 \mathrm{~s}$ between the FSI and rigid model in terms of both flow and pressure difference waves in systole (Figure $8 \&$ Figure 9). During diastole, time-shift between these waves varied with location along the descending aorta; these waves were in phase at the proximal location, but they were faster with the FSI model in the distal location. Pressure magnitudes were dampened in the FSI model (Figure $10 \&$ Figure 11, Table 7). By comparing the pressure waveforms between the foot of the inlet and outlet (Figure 10), the FSI model predicted a delay of $0.02 \mathrm{~s}$ in wave propagation from the inlet to the outlet. Regardless of the tear location (proximal/distal), the FSI model predicted lower systolic pressure, higher diastolic pressure, and thus lower pulse pressure (Figure $11 \&$ Table 7).

\subsection{Wall shear stress (WSS)}

Figure 12 shows a spatial representation of WSS patterns at peak systole and early diastole. At peak systole, $\mathrm{t}=0.16 \mathrm{~s}$, maximum WSS occurred when flow entered the FL through the proximal tear with high velocity and impinged upon the FL wall opposite to the proximal tear. The maximum WSS was about 53.3 Pa with the FSI model and $36.2 \mathrm{~Pa}$ with the rigid model. The WSS distribution was similar between the two models, except that the absolute WSS magnitudes in the TL computed with the rigid model were generally larger because of increased systolic TL velocity. During diastole, at $\mathrm{t}=0.41 \mathrm{~s}$, the direction of flow was reversed and flow entered the FL from the distal tear, hence WSS was the highest on the FL wall opposite the distal tear. The main discrepancy between these two models was the recirculation zones at the proximal FL, resulting in 70\% increment in WSS with the FSI model. Additionally, the wave shape of maximum WSS values over time was different between the FSI and rigid models (Figure 13), thus the temporal gradients of WSS would be substantially different. By accounting for wall compliance, there was high variability in WSS levels, which ranged from 2.5 $\mathrm{Pa}$ to $60.7 \mathrm{~Pa}$, as compared to the rigid model, which ranged from $0.7 \mathrm{~Pa}$ to $42.2 \mathrm{~Pa}$.

Time-averaged wall shear stress (TAWSS) and oscillatory shear index (OSI) for both rigid and FSI models are shown in Figure 14. High TAWSS was observed near the proximal and distal tears, while lower values were seen in the region between the tears and at both proximal and distal ends in the FL. Both rigid and FSI models demonstrated that regions with low TAWSS $(\leqslant 0.25 \mathrm{~Pa}$ ) coincided with high OSI. Nevertheless, the FSI model predicted a smaller area with low TAWSS $\left(177.44 \mathrm{~cm}^{2}\right.$ rigid vs. $\left.113.11 \mathrm{~cm}^{2} \mathrm{FSI}\right)$. 


\section{4 von. Mises stress}

von Mises stress distribution on the intimal flap is illustrated in Figure 15. von Mises stress is a measure used in material failure analysis and is a function of the three principle stresses in the body of TBAD. During peak systole, blood exited from the FL through the distal tear, hence the distal section of the flap, which curved towards the TL, experienced high wall stress $\left(>1 \times 10^{5} \mathrm{~N} / \mathrm{m}^{2}\right)$. During early diastole, the direction of flow through the proximal tear was reversed, hence the proximal section of the flap, which curved towards the TL experienced high wall stress. Persistent high wall stress in the flap towards the TL throughout the cardiac cycle, can lead to further expansion, or even rupture of the FL, while causing a narrowing of the smaller cross-sectional area of the TL.

\subsection{Discussion}

Most FSI studies on aortic dissection reported so far involve limited wall deformation of $<1 \mathrm{~mm}$ [15-17], except the most recent study reported by Baumler et. al. (2020) [23]. Hence, more work is needed to understand the influence of a highly mobile flap as observed in acute dissections $[12,13]$ on fluid dynamics in TBAD. Our current computational study addresses this issue by simulating physiological flap movement (Figure 5) and its effect on flow and pressure in a dissected aorta.

\subsection{Flap dynamics}

Dissection flap can move substantially during a cardiac cycle [12, 13]. Its motion is driven by the pressure difference between the true lumen (TL) and false lumen (FL). From the analysis of pressure distributions in the distal location, FL systolic pressure is higher than TL (Figure $9 \&$ Figure 11), driving the elastin-poor FL to further expansion, while causing a narrowing of the distal TL by up to $21.4 \%$. This is consistent with the in vivo study by Ganten et. al. (2009) who observed TL compression by as much as $29.0 \%$ [12]. At maximum compression of the TL, which could occur at the right renal artery (RRA) position [11], dynamic motion of the flap may cause obstruction of the important visceral branches originating from the TL, leading to malperfusion and end-organ ischemia [2]. As diastole begins, pressure increases in the distal TL, driving the flap to move towards the FL. The observed flap dynamics in the distal location is in agreement with data on acute dissection patients $[12,13,46]$. 


\subsection{Effect of flap motion on flow}

Simulation results show that flap displacement is more significant than the aortic walls that are relatively stiff (Figure $4 \&$ Table 6). Hence, it would be reasonable to expect that the flow dynamics is more sensitive to flap motion than the expansion/contraction of the aortic wall. The influence of flap movement is manifested through change in the TL to FL flow ratio and the extent of flow disturbance in the FL. At peak systole, the ratio of TL to FL flow is 83:17 with the mobile flap, compared to 88:12 with a rigid flap. Flap motion facilitates more flow to enter the FL through the proximal tear when it is pushed towards the FL at the proximal end. Similarly, Baumler et. al. (2020) reported that a more compliant flap (flap stiffness in the range of $20 \mathrm{kPa}$ to $800 \mathrm{kPa}$ ) caused reduction in TL flow by up to $10 \%$ at the level of pulmonary artery and their flow split results were validated using 4D MRI [23]. In addition, the dynamic interaction between the mobile flap and aortic flow causes more flow disturbances and recirculation (Figure 7) as measured through the use of a dimensionless parameter $\lambda_{2}$ [43]. Vortices tend to form near the proximal and distal tears where a large velocity gradient exists. The flow disturbance zones are quantified as vortical volume and percentage of disturbed flow. The total volume of vortices is $14.8 \mathrm{~cm}^{3}(5.8 \%)$ with the FSI model and $13.1 \mathrm{~cm}^{3}(5.2 \%)$ with the rigid model during systole. Greater vortical volume occurs during diastole due to flow reversal in the FL (34.9 $\mathrm{cm}^{3}$ FSI vs. $25.0 \mathrm{~cm}^{3}$ rigid) (13.5\% FSI vs. $9.8 \%$ rigid). Based on an in-vitro model using a compliant flow phantom of TBAD, Birjiniuk et. al. (2017) demonstrated that the action of a mobile intimal flap (maximum flap displacement $=14.3 \pm 0.5 \mathrm{~mm}$ near the distal tear) led to significant flow reversal in the proximal FL, as quantified by reverse flow index (percentage of blood volume ejected retrograde at a given slice normal to the aortic wall) [19]. This further demonstrates that large flap movement cannot be neglected because it has a profound influence on the flow dynamics.

\subsection{Effect of flap motion on WSS}

Hemodynamic parameter such as wall shear stress (WSS) is a key factor influencing thrombus formation within the FL [34]. Spatial distributions of WSS are not remarkably different between the FSI and rigid models (Figure 12), but quantitative differences cannot be ignored. In particular, the FSI model predicts a larger variability in maximum WSS over a cardiac cycle (Figure 13). Compared to the rigid model, our FSI results show that mean WSS in the TL is $33 \%$ lower at peak systole when flow in the TL is obstructed by the distal flap, while flap motion-induced flow recirculation in the proximal FL during diastole causes local WSS to increase by $70 \%$. As a result of this increase in WSS in the FSI model, the area of low 
TAWSS regions (TAWSS $\leqslant 0.25 \mathrm{~Pa}$ [47]) is markedly reduced when compared to the rigid model (Figure 14). The surface area with low TAWSS in the FL is $113.11 \mathrm{~cm}^{2}(44.8 \%)$ with the FSI model and $177.44 \mathrm{~cm}^{2}(73.8 \%)$ with the rigid model. This finding is consistent with Baumler et. al. (2020) [23], and is likely to affect FL thrombosis [47]. High values of WSS around tears are more likely to trigger the activation of platelets trapped in vortices. The activated platelets interact with the surface of the FL wall and further release factors that contribute to the accumulation of platelets at an injury site, thereby accelerating FL thrombosis [48]. Another widely used WSS index is oscillatory shear index (OSI). High OSI values are found to coincide with areas of low TAWSS in our study, which is comparable to Alimohammadi et. al. (2015) [16]. However, the locations of high OSI/low TAWSS regions are different in our study due to differences in model geometry and the extent of flap motion.

\subsection{Effect of flap motion on pressure}

Measurements of blood pressure (BP) in TBAD patients can help with patient stratification, assess blood pressure-related risks, and guide clinical management [49]. By accounting for wall compliance, as blood is ejected into the aorta during systole, the aortic wall expands to accommodate the increase in blood volume, resulting in a time-delayed, dampened systolic pressure in the FSI model (Figs. 9 - 11). During diastole, the FSI model predicts a smaller pressure change (i.e. a higher diastolic pressure), and hence a lower pulse pressure (PP) (Table 7), which is in good agreement with [10]. The PP obtained with the FSI and rigid models differs by $-42.16 \%$, suggesting that the rigid model could substantially overpredict PP. In addition, the rigid model has faster wave propagation from the inlet to the outlet (Figure 10). The inability of the rigid model to accurately capture the wave propagation phenomena may significantly affect the pressure difference analysis $\left(\Delta P=P_{T L}-P_{F L}\right)$ of dissection patients (Figure 9), which is of clinical significance. Increased FL pressure may lead to aortic complications such as obstruction of blood flow in the TL and FL dilatation $[2,36]$. 


\subsection{Wall stress analysis}

Other than hemodynamics, the FSI model can also be used to predict wall stress (Figure 15), which has been reported to be a more reliable parameter for the assessment of rupture risk in patients with abdominal aortic aneurysm (AAA) as compared to the maximum diameter [50]. Wall stress is not directly measurable in vivo, but can be determined by means of finite element analysis or FSI simulations. The present FSI model revealed high von. Mises stress concentration in the flap regions that always curved towards the TL, leading to compression of the TL. The maximum von. Mises stresses in the proximal and distal flap are 262 and 341 $\mathrm{kN} / \mathrm{m}^{2}$ respectively. A wall stress of $280 \mathrm{kN} / \mathrm{m}^{2}$ was used as a threshold to predict the rupture risk of AAA [51]. Hence, the distal flap region would be more prone to rupture during periods of sudden, increased systolic pressure [52]. Further FSI studies will be needed in order to assess the peak wall stress threshold value for rupture risk prediction of TBAD patients.

\subsection{Limitations}

The goal of this work is to study the fully coupled interaction between pulsatile blood flow and thin dissected aortic wall for a scenario relevant to acute dissection. Several anatomic simplifications and assumptions are made, including exclusion of the vessel branches and planar geometry. At a physiological cardiac output of $5 \mathrm{~L} / \mathrm{min}$ [53] with $15.0 \%-21.8 \%$ of the aortic flow going into the supra-aortic branches [8, 53-55], flow in the descending aorta would be around $3.91-4.25 \mathrm{~L} / \mathrm{min}$. In our model the simulated flow rate in the descending aorta was 3.85 L/min which is close to the expected range. Therefore, this geometric assumption is not expected to have a major impact on the predicted flow and pressure distributions in the dissected descending aorta.

Owing to the lack of material characterisation of dissected aorta and intimal flap, both are assumed to be linear elastic and isotropic under zero residual stress state. For this reason, the wall stress values presented here do not represent the actual stress values. Calculation of residual stress may involve complex non-linear anisotropic material analysis where further assumptions and approximations are required [56]. Methods to account for residual stress in FSI analysis of large arteries have been introduced [23, 57], whereby a tissue prestress tensor is applied to the arterial wall. It has been found that neglecting prestress in the arterial wall can cause over expansion of the aorta and unphysiological stretching of the intimal flap, which can influence the predicted flow and pressure. Although prestress is not considered in the present study, the incorporation of five pairs of intercostal arteries in the descending thoracic aorta as fixed constraints may counterbalance the inflation of arterial wall. 
Nevertheless, this simplified model retains important physical features to mimic realistic clinical situations. Specifically, it takes into account the effect of drastic flap movement on the hemodynamics of TBAD, which was not possible in most previous FSI studies owing to numerical difficulties related to poor mesh quality and negative volume elements. Our computational results are compared with relevant data in the literature and satisfactory agreement is achieved. Significant differences between the FSI and rigid-wall models justify the need to extend the current modelling approach to patient-specific cases and validate our computational results with 4D flow MRI data for direct comparison.

\subsection{Conclusion}

Our monolithic fully coupled FSI computational framework shows that large flap motion has a significant influence on the predicted flow and pressure distributions. The flap movement reaches $4.59 \mathrm{~mm}$ during peak systole, collapsing the true lumen with a possibility of dynamic blood flow obstruction and severe malperfusion of the distal vasculature. Flap motion increases flow resistance in the TL, leading to more flow $(\sim 5 \%)$ entering the FL. Furthermore, flap movement causes more disturbed flow in the FL as visualised through $\lambda_{2}$ criterion and evaluated in terms of vortex volume. This results in quantitative differences in wall shear stress, which is a key factor influencing thrombus formation within the FL. Accounting for wall compliance has an effect on pressure dampening in the true and false lumens, thereby affecting pressure measures, which may serve as potential prognostic indicators for acute TBAD patients that are likely to develop late complications. The current simplified model provides valuable insights into the effect of flap motion on hemodynamics and its associated complications.

\section{Acknowledgments}

This work was supported by the Royal Society-Newton Advanced Fellowship No. NA170094. 


\section{References}

1. Peterss S, Mansour AM, Ross JA, et al. Changing Pathology of the Thoracic Aorta from Acute to Chronic Dissection: Literature Review and Insights. Journal of the American College of Cardiology. 2016; 68(10): 1054-1065. doi: 10.1016/j.jacc.2016.05.091.

2. Crawford TC, Beaulieu RJ, Ehlert BA, Ratchford EV, Black JH. Malperfusion syndromes in aortic dissections. Vascular medicine (London, England). 2016; 21(3): 264-273. doi: 10.1177/1358863X15625371.

3. Akin I, Kische S, Ince H, Nienaber CA. Indication, Timing and Results of Endovascular Treatment of Type B Dissection. European Journal of Vascular and Endovascular Surgery. 2009; 37(3): 289-296. doi: 10.1016/j.ejvs.2008.12.004.

4. Cavalcante JL, Lima JAC, Redheuil A, Al-Mallah MH. Aortic Stiffness: Current Understanding and Future Directions. Journal of the American College of Cardiology. 2011; 57(14): 1511-1522. doi: 10.1016/j.jacc.2010.12.017.

5. Bortone AS, Schena S, D'Agostino D, et al. Immediate versus delayed endovascular treatment of post-traumatic aortic pseudoaneurysms and type B dissections: retrospective analysis and premises to the upcoming European trial. Circulation. 2002; 106(12 Suppl 1): 1234-1240. doi: 10.1161/01.cir.0000039154.47029.a4.

6. Patel PD,Arora RR. Pathophysiology, diagnosis, and management of aortic dissection. Journal of the American College of Cardiology. 2008; 2(6): 439-468. doi: $10.1177 / 1753944708090830$.

7. Chen D, Müller-Eschner M, von Tengg-Kobligk H, et al. A patient-specific study of type-B aortic dissection: evaluation of true-false lumen blood exchange. Biomedical engineering online. 2013; 12: 65. doi: 10.1186/1475-925X-12-65.

8. Tse KM, Chiu P, Lee HP, Ho P. Investigation of hemodynamics in the development of dissecting aneurysm within patient-specific dissecting aneurismal aortas using computational fluid dynamics (CFD) simulations. Journal of Biomechanics. 2011; 44(5): 827-836. doi: 10.1016/j.jbiomech.2010.12.014.

9. Cheng Z, Tan FPP, Riga CV, et al. Analysis of Flow Patterns in a Patient-Specific Aortic Dissection Model. Journal of Biomechanical Engineering. 2010; 132(5). doi: 10.1115/1.4000964.

10. Rudenick PA, Bijnens BH, Segers P, García-Dorado D, Evangelista A. Assessment of Wall Elasticity Variations on Intraluminal Haemodynamics in Descending Aortic Dissections Using a Lumped-Parameter Model. PLOS ONE. 2015; 10(4): e0124011. doi: 10.1371/journal.pone.0124011.

11. Bonfanti M, Franzetti G, Maritati G, et al. Patient-specific haemodynamic simulations of complex aortic dissections informed by commonly available clinical datasets. Medical Engineering \& Physics. 2019: 593780. doi: 10.1101/593780.

12. Ganten M, Weber T, Tengg-Kobligk VH, et al. Motion characterization of aortic wall and intimal flap by ECG-gated CT in patients with chronic B-dissection. European Journal of Radiology. 2009; 72: 146-153. doi: 10.1016/j.ejrad.2008.06.024.

13. Yang S, Li X, Chao B, et al. Abdominal aortic intimal flap motion characterization in acute ortic dissection: assessed with retrospective ECG-gated thoracoabdominal aorta dual-source CT angiography. PLOS One 2014; 9(2): e87664. doi: 10.1371/journal.pone.0087664.

14. Karmonik C, Duran C, Shah DJ, et al. Preliminary findings in quantification of changes in septal motion during follow-up of type B aortic dissections. Journal of Vascular Surgery. 2012; 55(5): 1419-1426.e1. doi: 10.1016/j.jvs.2011.10.127. 
15. Chen HY, S.V. Peelukhana, Z.C. Berwick, et al. Fluid-structure interaction simulations of aortic dissection with bench validation. European Journal of Vascular and Endovascular Surgery. 2016; 52(5): 589 - 595. doi: 10.1016/j.ejvs.2016.07.006.

16. Alimohammadi M, Sherwood JM, Karimpour M, et al. Aortic dissection simulation models for clinical support: fluid-structure interaction vs. rigid wall models. BioMedical Engineering OnLine. 2015; 14(34). doi: 10.1186/s12938-015-0032-6.

17. Qiao Y, Zeng Y, Ding Y, et al. Numerical simulation of two-phase non-Newtonian blood flow with fluid-structure interaction in aortic dissection. Computer Methods in Biomechanics and Biomedical Engineering. 2019; 22(6): 620-630. doi: 10.1080/10255842.2019.1577398.

18. Shuib A, Hoskins P, Easson W. Experimental investigation of particle distribution in a flow through a stenosed artery. Journal of Mechanical Science and Technology. 2011; 25(2): 357-364. doi: 10.1007/s12206-010-1232-4.

19. Birjiniuk J, Timmins LH, Young M, et al. Pulsatile Flow Leads to Intimal Flap Motion and Flow Reversal in an In Vitro Model of Type B Aortic Dissection. Cardiovascular Engineering and Technology. 2017; 8(3): 378-389. doi: 10.1007/s13239-017-0312-3.

20. Chong MY, Pirola S, Johari NH, et al. One-way fluid-structure interaction analysis of intimal flap dynamics for acute-to-chronic type B aortic dissection. In: 6th International Conference on Computational and Mathematical Biomedical Engineering. Tohoku University, Katahira Campus, Sendai City, Japan: CMBE Proceedings 2019; 2: 414 417.

21. Brummelen EHv. Added mass effects of compressible and incompressible flows in fluid-structure interaction. Journal of Applied Mechanics. 2009; 76(2): 021206. doi: 10.1115/1.3059565.

22. Michler C, Hulshoff SJ, van Brummelen EH, de Borst R. A monolithic approach to fluid-structure interaction. Computers \& Fluids. 2004; 33(5): 839-848. doi: 10.1016/j.compfluid.2003.06.006.

23. Baumler K, Vedula V, Sailer AM, et al. Fluid-structure interaction simulations of patient-specific aortic dissection. Biomechanics and Modeling in Mechanobiology 2020. doi: 10.1007/s10237-020-01294-8.

24. Sang h, Ngo L, Muhammad S, Jeon B, Choi H. A comparative study between partitioned and monolithic methods for the problems with 3D fluid-structure interaction of blood vessels. Journal of Mechanical Science and Technology. 2017; 31: 281-287. doi: 10.1007/s12206-016-1230-2.

25. Blount KJ,Hagspiel KD. Aortic Diameter, True Lumen, and False Lumen Growth Rates in Chronic Type B Aortic Dissection. American Journal of Roentgenology. 2009; 192(5): W222-W229. doi: 10.2214/AJR.07.3986.

26. Åstrand H, Rydén-Ahlgren A, Sandgren T, Länne T. Age-related increase in wall stress of the human abdominal aorta: An in vivo study. Journal of Vascular Surgery. 2005; 42(5): 926-931. doi: 10.1016/j.jvs.2005.07.010.

27. LePage MA, Quint LE, Sonnad SS, Deeb GM, Williams DM. Aortic Dissection. American Journal of Roentgenology. 2001; 177(1): 207-211. doi: 10.2214/ajr.177.1.1770207.

28. Khoynezhad A, Walot I, Kruse MJ, et al. Distribution of intimomedial tears in patients with type B aortic dissection. Journal of Vascular Surgery. 2010; 52(3): 562-568. doi: 10.1016/j.jvs.2010.04.036.

29. Evangelista A, Salas A, Ribera A, et al. Long-term outcome of aortic dissection with patent false lumen: predictive role of entry tear size and location. Circulation. 2012; 125(25): 3133-3141. doi: 10.1161/circulationaha.111.090266. 
30. Mensel B, Kuhn JP, Schneider T, Quadrat A, Hegenscheid K. Mean thoracic aortic wall thickness determination by cine MRI with steady-state free precession: validation with dark blood imaging. Academic Radiology 2013; 20(8): 1004-1008. doi: 10.1016/j.acra.2013.03.014.

31. Ma T, Dong ZH, Wang S, et al. Computational investigation of interaction between stent graft and aorta in retrograde type A dissection after thoracic endovascular aortic repair for type B aortic dissection. Journal of Vascular Surgery. 2018; 68(6s): 14S21S.e2. doi: 10.1016/j.jvs.2018.06.008.

32. Quemada D. Rheology of concentrated disperse systems III. General features of the proposed non-newtonian model. Comparison with experimental data. Rheologica Acta. 1978; 17(6): 643-653. doi: 10.1007/BF01522037.

33. Marcinkowska-Gapińska A, Gapinski J, Elikowski W, Jaroszyk F, Kubisz L. Comparison of three rheological models of shear flow behavior studied on blood samples from post-infarction patients. Medical and Biological Engineering and Computing. 2007; 45(9): 837-844. doi: 10.1007/s11517-007-0236-4.

34. Menichini $\mathrm{C}, \mathrm{Xu} \mathrm{XY}$. Mathematical modeling of thrombus formation in idealized models of aortic dissection: initial findings and potential applications. Journal of Mathematical Biology. 2016; 73(5): 1205-1226. doi: 10.1007/s00285-016-0986-4.

35. Xiao N, Alastruey J, Alberto Figueroa C. A systematic comparison between 1-D and 3-D hemodynamics in compliant arterial models. International Journal for Numerical Method in Biomedical Engineering. 2014; 30(2): 204-231. doi: 10.1002/cnm.2598.

36. Tsai TT, Schlicht MS, Khanafer K, et al. Tear size and location impacts false lumen pressure in an ex vivo model of chronic type B aortic dissection. Journal of Vascular Surgery. 2008; 47(4): 844-851. doi: 10.1016/j.jvs.2007.11.059.

37. Nerem RM, Seed WA, Wood NB. An experimental study of the velocity distribution and transition to turbulence in the aorta. Journal of Fluid Mechanics. 2006; 52(1): 137 160. doi: 10.1017/S0022112072003003.

38. Khanafer K, Duprey A, Zainal M, et al. Determination of the elastic modulus of ascending thoracic aortic aneurysm at different ranges of pressure using uniaxial tensile testing. The Journal of Thoracic and Cardiovascular Surgery. 2011; 142(3): 682-686. doi: 10.1016/j.jtcvs.2010.09.068.

39. Thubrikar M. Vascular Mechanics and Pathology. 2007. doi: 10.1007/978-0-38768234-1.

40. Winslow AM. Numerical solution of the quasilinear poisson equation in a nonuniform triangle mesh. Journal of Computational Physics. 1966; 1(2): 149-172. doi: 10.1016/0021-9991(66)90001-5.

41. Karman SL. Virtual Control Volumes for Two-Dimensional Unstructured Elliptic Smoothing. In: Proceedings of the 19th International Meshing Roundtable. Berlin, Heidelberg: Springer Berlin Heidelberg. 2010: 121-142.

42. COMSOL multiphysics reference manual $1-1742$.

43. Jeong J,Hussain F. On the identification of a vortex. Journal of Fluid Mechanics. 2006; 285: 69-94. doi: 10.1017/S0022112095000462.

44. Cucitore R, Quadrio M, Baron A. On the effectiveness and limitations of local criteria for the identification of a vortex. European Journal of Mechanics - B/Fluids. 1999; 18(2): 261-282. doi: 10.1016/S0997-7546(99)80026-0.

45. Chan BT, Ahmad Bakir A, Al Abed A, et al. Impact of myocardial infarction on intraventricular vortex and flow energetics assessed using computational simulations. International Journal for Numerical Methods in Biomedical Engineering. 2019; 35(6): e3204. doi: 10.1002/cnm.3204. 
46. Kotval PS, Babu SC, Fakhry J, Cozzi A, Barakat K. Role of the intimal flap in arterial dissection: sonographic demonstration. American Journal of Roentgenology. 1988; 150(5): 1181-1182. doi: 10.2214/ajr.150.5.1181.

47. Menichini C, Cheng Z, Gibbs RG, Xu XY. Predicting false lumen thrombosis in patient-specific models of aortic dissection. Journal of The Royal Society Interface. 2016; 13(124): 1-11. doi: 10.1098/rsif.2016.0759.

48. Mustard JF, Packham MA, Kinlough-Rathbone RL. Platelets and thrombosis in the development of atherosclerosis and its complications. Advances in Experimental Medicine and Biology. 1978; 102: 7-30. doi: 10.1007/978-1-4757-1217-9_2.

49. Pickering TG, Hall JE, Appel LJ, et al. Recommendations for blood pressure measurement in humans and experimental animals: part 1: blood pressure measurement in humans: a statement for professionals from the Subcommittee of Professional and Public Education of the American Heart Association Council on High Blood Pressure Research. Circulation. 2005; 111(5): 697-716. doi: 10.1161/01.cir.0000154900.76284.f6.

50. Fillinger MF, Marra SP, Raghavan ML, Kennedy FE. Prediction of rupture risk in abdominal aortic aneurysm during observation: Wall stress versus diameter. Journal of Vascular Surgery. 2003; 37(4): 724-732. doi: 10.1067/mva.2003.213.

51. Hall AJ, Busse EF, McCarville DJ, Burgess JJ. Aortic wall tension as a predictive factor for abdominal aortic aneurysm rupture: improving the selection of patients for abdominal aortic aneurysm repair. Annals of Vascular Surgery. 2000; 14(2): 152-157. doi: $10.1007 / \mathrm{s} 100169910027$.

52. Sandler H,Dodge Harold T. Left Ventricular Tension and Stress in Man. Circulation Research. 1963; 13(2): 91-104. doi: 10.1161/01.RES.13.2.91.

53. Zamir M, Sinclair P, Wonnacott TH. Relation between diameter and flow in major branches of the arch of the aorta. Journal of Biomechanics. 1992; 25(11): 1303-1310. doi: 10.1016/0021-9290(92)90285-9.

54. Pirola S, Cheng Z, Jarral OA, et al. On the choice of outlet boundary conditions for patient-specific analysis of aortic flow using computational fluid dynamics. Journal of Biomechanics. 2017; 60: 15-21. doi: 10.1016/j.jbiomech.2017.06.005.

55. Barakat AI, Marini RP, Colton CK. Measurement of flow rates through aortic branches in the anesthetized rabbit. Laboratory Animal Science. 1997; 47(2): 184-189.

56. Raghavan ML, Ma B, Fillinger MF. Non-invasive determination of zero-pressure geometry of arterial aneurysms. Annals of Biomedical Engineering. 2006; 34(9): 14141419. doi: 10.1007/s10439-006-9115-7.

57. Hsu M-C,Bazilevs Y. Blood vessel tissue prestress modeling for vascular fluidstructure interaction simulation. Finite Elements in Analysis and Design. 2011; 47(6): 593-599. doi: 10.1016/j.finel.2010.12.015. 


\section{List of tables}

Table 1: Geometric features of the idealised model employed in this study

\begin{tabular}{lcc}
\hline Geometric features & $\begin{array}{c}\text { Dimensions } \\
(\mathrm{mm})\end{array}$ & References \\
\hline Aortic diameter & 43.20 & {$[25]$} \\
True lumen diameter & 19.40 & {$[25]$} \\
False lumen diameter & 23.00 & {$[26]$} \\
Intimal flap thickness & 0.80 & {$[27]$} \\
Intimal flap shape & Crescent & {$[28]$} \\
Location of proximal tear from & 23.41 & {$[28]$} \\
LSA & 283.50 & {$[29]$} \\
Location of distal tear from LSA & 10.00 & {$[29]$} \\
Entry tear size & 10.00 & \\
Re-entry tear size & 2 & \\
Number of tears & 319.00 & \\
Length of descending aorta & 1.60 & \\
Aortic wall thickness & & \\
\hline
\end{tabular}

Table 2: Material properties of structural domain used in the computational model.

\begin{tabular}{lccc}
\hline Material Properties & Value & Units & References \\
\hline Wall density, $\rho_{\text {solid }}$ & 1250.00 & $\mathrm{~kg} / \mathrm{m}^{3}$ & \\
Young's modulus of aortic wall & 2.70 & $\mathrm{MPa}$ & {$[38,39]$} \\
Young's modulus of intimal flap & 6.75 & $\mathrm{MPa}$ & {$[20]$} \\
Poisson ratio & 0.49 & & {$[39]$}
\end{tabular}


Table 3: Details of the mesh used in mesh independence tests.

\begin{tabular}{ccccc}
\hline \multicolumn{2}{c}{ Number of mesh elements } & \multicolumn{2}{c}{ Average mesh size } \\
\hline Coupled domains & Fluid domain & Structural domain & $\begin{array}{c}\text { Coupled domains } \\
(\mathrm{mm})\end{array}$ & $\begin{array}{c}\text { Tears } \\
(\mathrm{mm})\end{array}$ \\
\hline 75,000 & 60,000 & 15,000 & 7.8 & 2.2 \\
185,000 & 160,000 & 25,000 & 5.3 & 1.7 \\
400,000 & 350,000 & 50,000 & 4.1 & 1.3 \\
\hline
\end{tabular}

Table 4: Mesh independence test results showing comparison of average pressure, velocity and wall shear stress (WSS) between different meshes for the fluid domain.

\begin{tabular}{ccccccc}
\hline $\begin{array}{c}\text { Total } \\
\text { number of } \\
\text { elements }\end{array}$ & $\begin{array}{c}\text { Average } \\
\text { pressure } \\
(\mathrm{Pa})\end{array}$ & $\begin{array}{c}\text { Difference } \\
(\%)\end{array}$ & $\begin{array}{c}\text { Average } \\
\text { velocity } \\
(\mathrm{m} / \mathrm{s})\end{array}$ & $\begin{array}{c}\text { Difference } \\
(\%)\end{array}$ & $\begin{array}{c}\text { Average } \\
\text { WSS } \\
(\mathrm{Pa})\end{array}$ & $\begin{array}{c}\text { Difference } \\
(\%)\end{array}$ \\
\hline 75,000 & 3318.900 & 0.209 & 0.552 & 0.169 & 1.011 \\
185,000 & 3338.100 & 0.575 & 0.210 & & 0.171 & 1.206 \\
400,000 & 3356.000 & 0.533 & 0.211 & & 0.173 & \\
\hline
\end{tabular}

Table 5: Mesh independence test results showing comparison of wall displacement, flap displacement and von. Mises stress maxima between different meshes for the structural domain.

\begin{tabular}{|c|c|c|c|c|c|c|}
\hline $\begin{array}{c}\text { Total } \\
\text { number of } \\
\text { elements }\end{array}$ & $\begin{array}{c}\text { Maximum } \\
\text { wall } \\
\text { displacement } \\
(\mathrm{mm})\end{array}$ & $\begin{array}{c}\text { Difference } \\
(\%)\end{array}$ & $\begin{array}{l}\text { Maximum } \\
\text { flap } \\
\text { displacement } \\
(\mathrm{mm})\end{array}$ & $\begin{array}{c}\text { Difference } \\
(\%)\end{array}$ & $\begin{array}{l}\text { Maximum } \\
\text { von. } \\
\text { Mises } \\
\text { stress } \\
\left(10^{5} \mathrm{~N} / \mathrm{m}^{2}\right)\end{array}$ & $\begin{array}{c}\text { Difference } \\
(\%)\end{array}$ \\
\hline \multirow[t]{2}{*}{75,000} & 0.907 & & 4.601 & & 4.865 & \\
\hline & & -1.910 & & 3.155 & & 12.184 \\
\hline \multirow[t]{2}{*}{185,000} & 0.890 & & 4.752 & & 5.540 & \\
\hline & & -0.390 & & 0.582 & & 2.465 \\
\hline 400,000 & 0.887 & & 4.779 & & 5.680 & \\
\hline
\end{tabular}

Table 6: Displacement of the aortic wall and flap obtained from FSI model.

\begin{tabular}{lcc}
\hline & Range of movement $[\mathrm{mm}]$ & Mean \pm SD [mm] \\
\hline Wall & $1.561-2.068$ & $1.792 \pm 0.153$ \\
Flap & $2.105-4.587$ & $2.783 \pm 0.591$ \\
\hline
\end{tabular}


Table 7: Comparison of pressures at the proximal and distal tears.

\begin{tabular}{ccccccc}
\hline & \multicolumn{3}{c}{ Proximal tear } & & Distal tear & \\
\cline { 2 - 7 } Model & $\begin{array}{c}\text { Systolic } \\
\text { pressure, } \\
\text { SP } \\
{[\mathrm{mmHg}]}\end{array}$ & $\begin{array}{c}\text { Diastolic } \\
\text { pressure, } \\
\text { DP }[\mathrm{mmHg}]\end{array}$ & $\begin{array}{c}\text { Pulse } \\
\text { pressure, } \\
\text { PP } \\
{[\mathrm{mmHg}]}\end{array}$ & $\begin{array}{c}\text { Systolic } \\
\text { pressure, SP } \\
{[\mathrm{mmHg}]}\end{array}$ & $\begin{array}{c}\text { Diastolic } \\
\text { pressure, DP } \\
{[\mathrm{mmHg}]}\end{array}$ & $\begin{array}{c}\text { Pulse } \\
\text { pressure, PP } \\
{[\mathrm{mmHg}]}\end{array}$ \\
\hline FSI & 105.700 & 76.037 & 29.663 & 107.178 & 75.422 & 31.756 \\
Rigid & 111.895 & 69.752 & 42.143 & 114.573 & 69.403 & 45.170 \\
\hline
\end{tabular}




\section{List of figures}

(a)

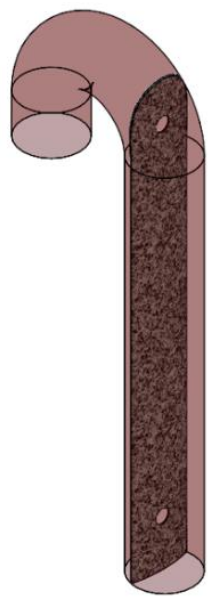

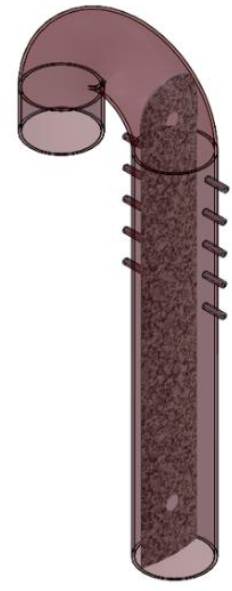

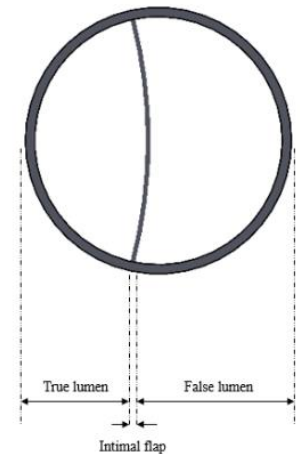

Figure 1: Idealised model for acute dissection in this study. (a) Fluid geometry, (b) Structural geometry with a wall thickness of $1.6 \mathrm{~mm}$, (c) Flap configuration.

(a)

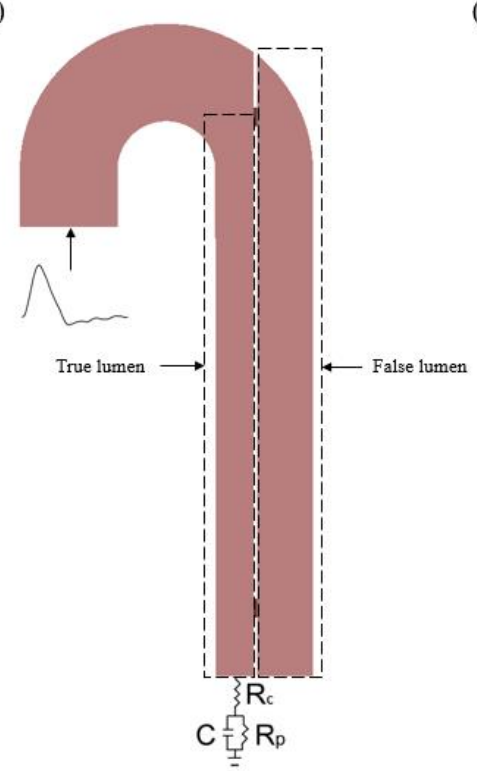

(b)

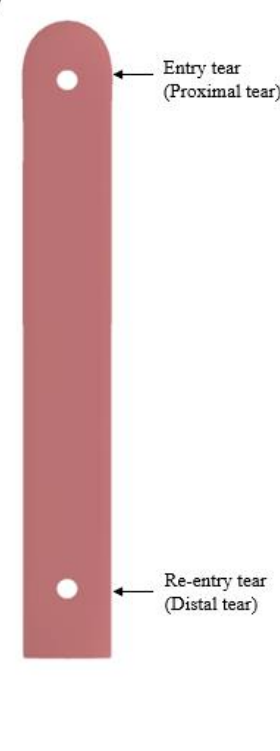

(c)

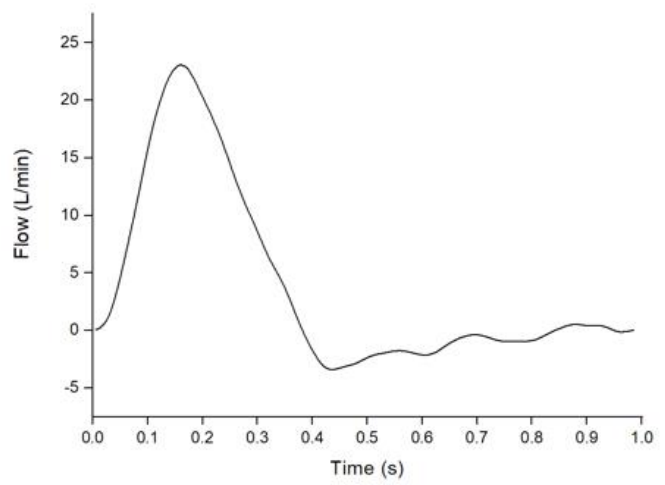

Figure 2: (a) Geometric model with inlet and outlet boundary conditions. $\mathbf{R}_{\mathrm{c}}=$ impedance of the aorta, $\mathrm{C}=$ compliance of aortic walls, $\mathrm{R}_{\mathrm{p}}=$ resistance of peripheral vessels, (b) Flap with two tears configuration, (c) Inflow waveform 
(a)

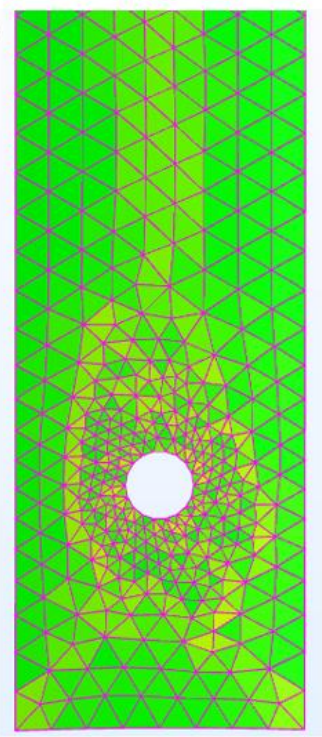

(b)

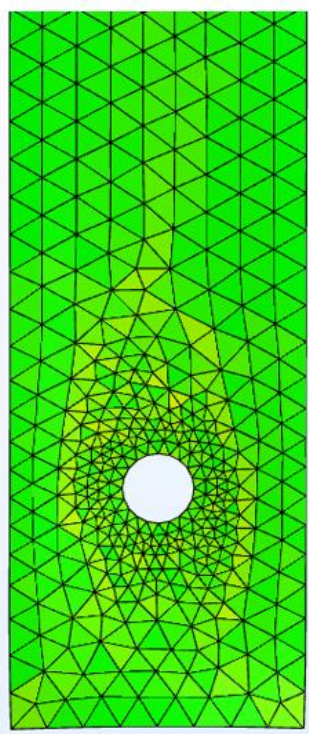

(c)

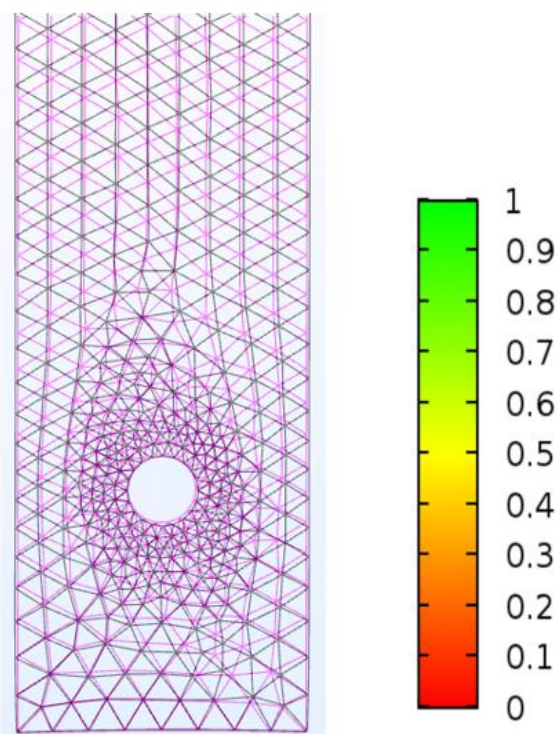

Figure 3: TL surface mesh near to the distal tear, with the color bar representing the mesh element quality. (a) Initial mesh, (b) Winslow mesh smoothing at 0.16s, (c) Superimposition of Figure 3(a) and 3(b) to show Winslow smoothing allows the mesh nodes to be moved to conform flap motion. To have better visualisation on the effect of Winslow mesh smoothing, Figures 3(a) and 3(b) were superimposed, with the wireframe color remained in pink for 3(a) and in black for $3(\mathrm{~b})$.

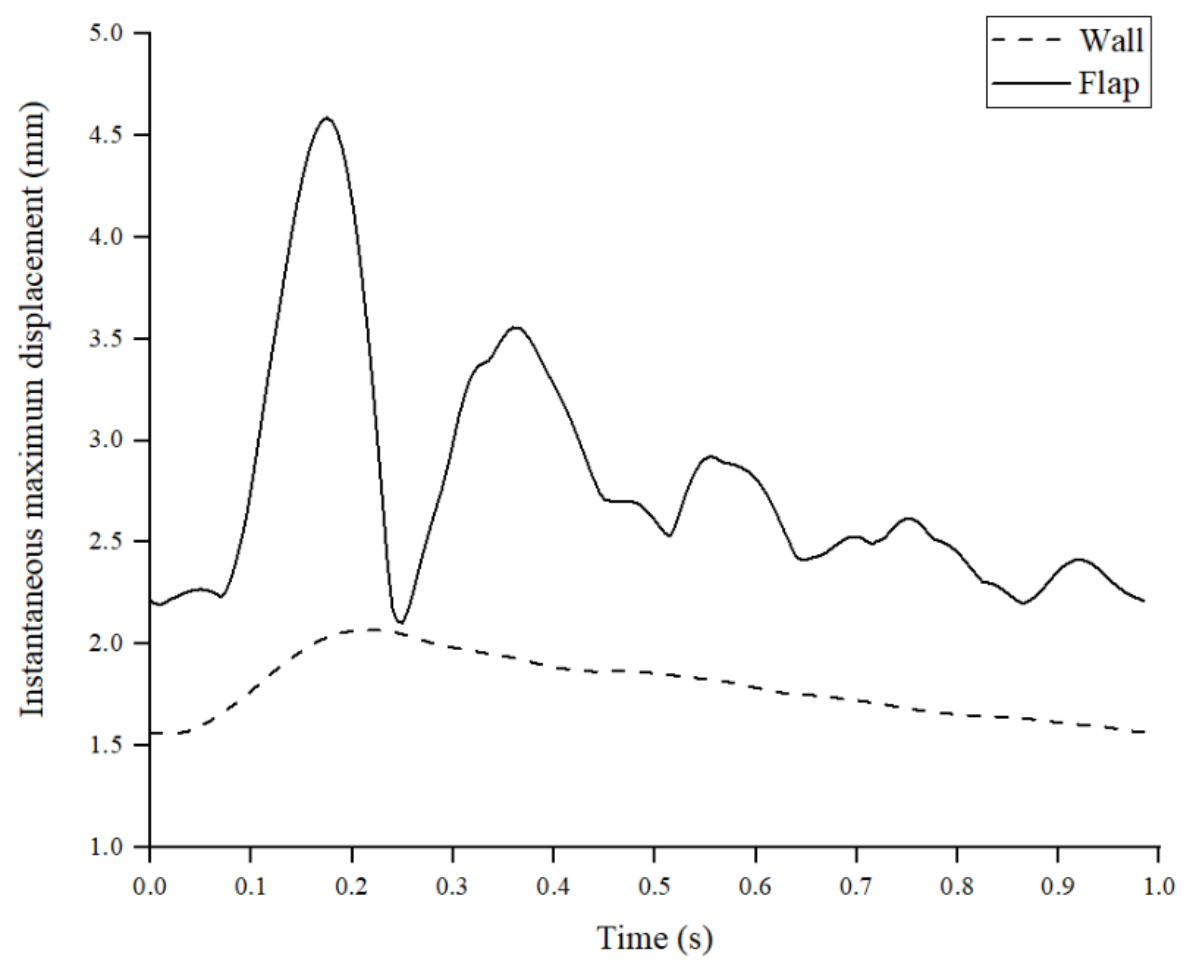

Figure 4: Temporal variations of displacement for aortic wall and flap obtained from FSI model. 


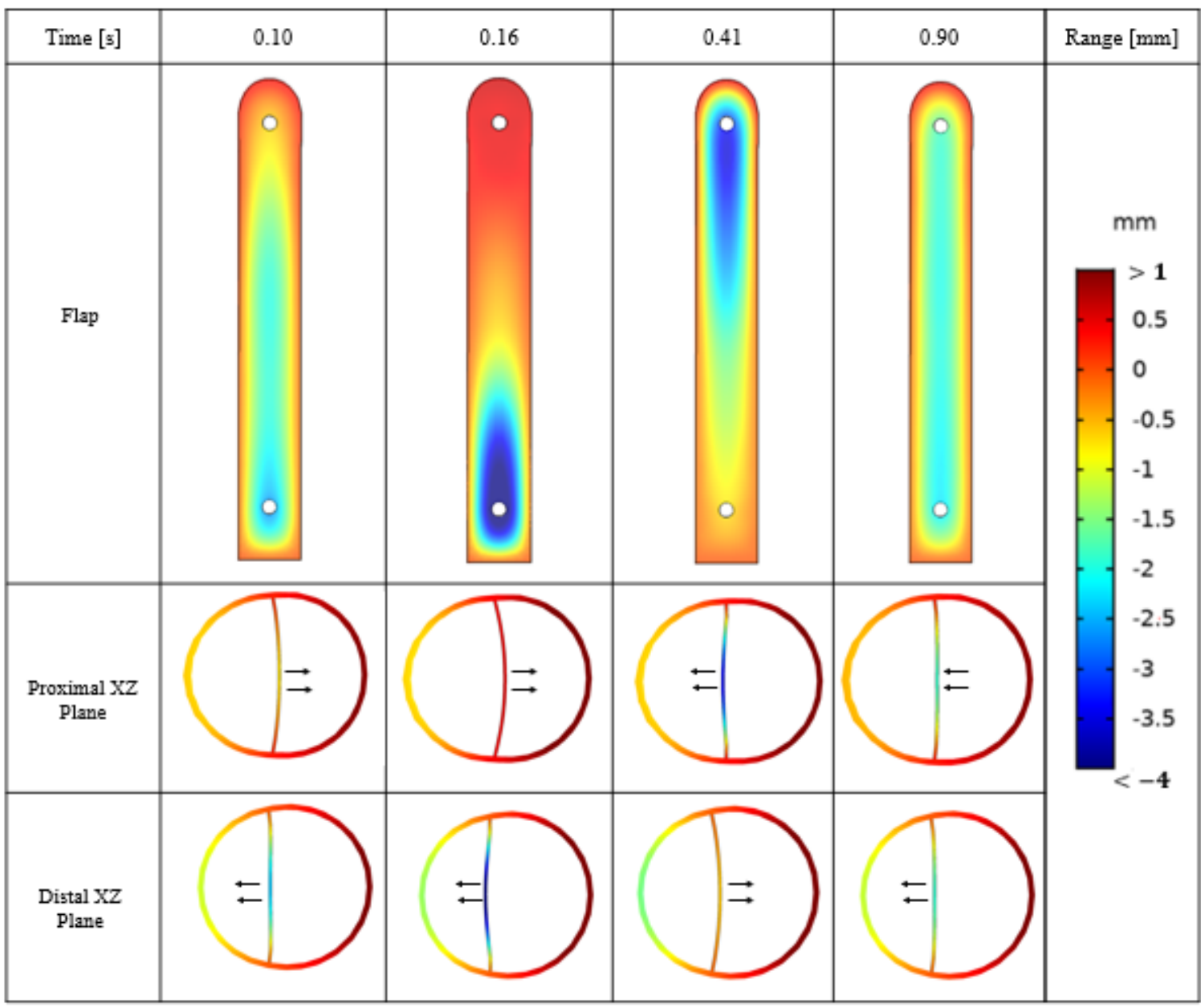

Figure 5: Flap displacement and configurations in proximal and distal locations obtained from FSI model. Negative displacement sign indicates that the flap moves towards the TL (i.e. curved to the left, as indicated by the arrows) or vice versa. 


Model

Figure 6: Blood flow fields predicted by rigid and FSI models. 2 different time instants along the cardiac cycle representative of peak systole and early diastole phases are chosen, at $0.16 \mathrm{~s}$ and $0.41 \mathrm{~s}$ respectively. There are close-up views at proximal and distal sections of descending aorta. 


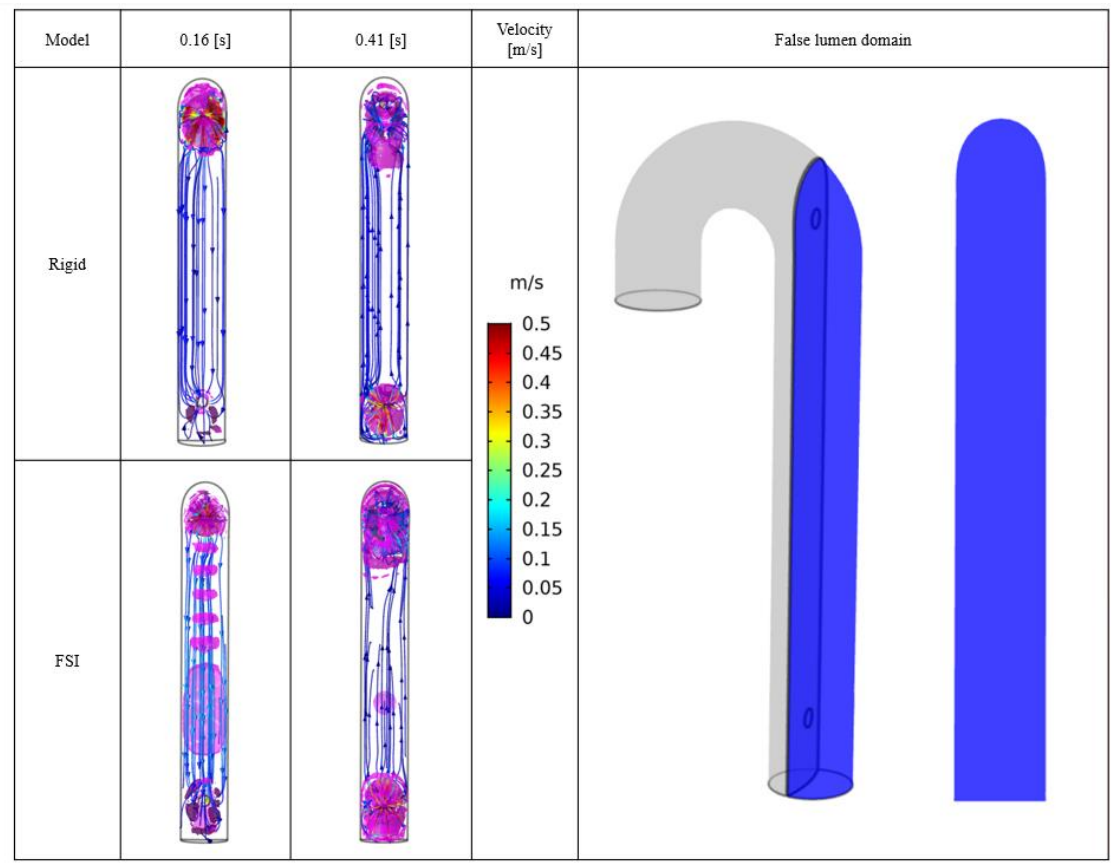

Figure 7: Vortical regions in the FL (highlighted in magenta) estimated by rigid and FSI models, along with superimposition of corresponding instantaneous velocity streamlines at $0.16 \mathrm{~s}$ and $0.41 \mathrm{~s}$ respectively. Identification of vortical regions through $\lambda_{2}$-criterion only focused in the FL domain in blue (right). Colour bar represents the velocity magnitude in $\mathrm{m} / \mathrm{s}$.

(a)

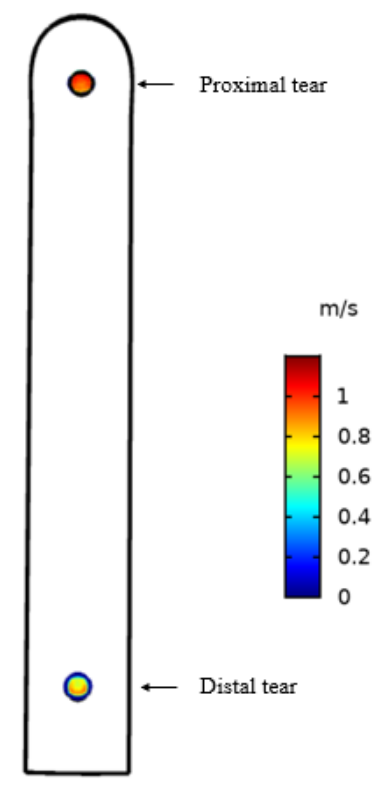

(b)
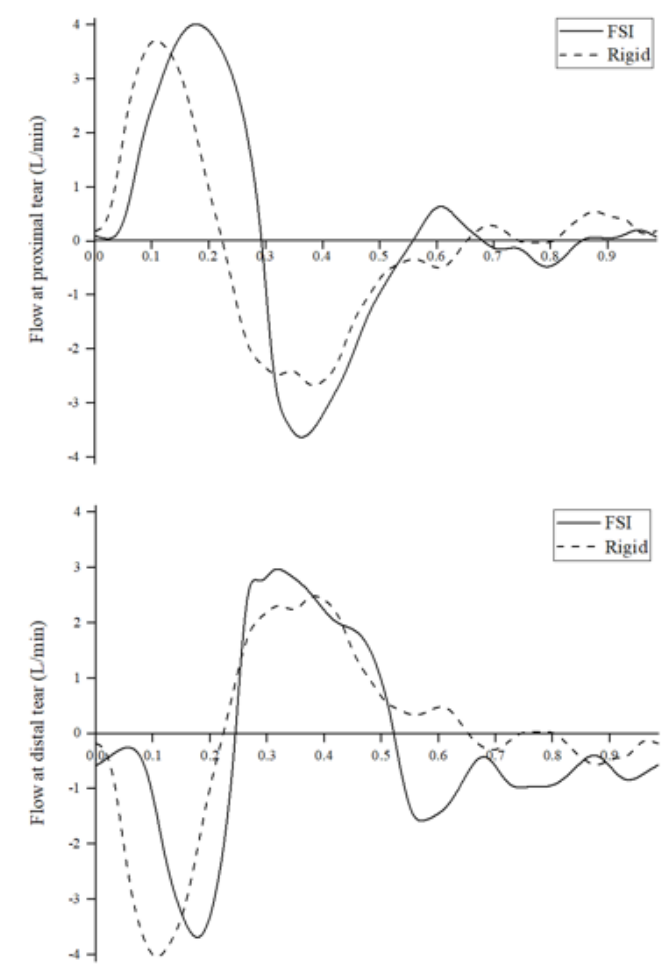

Figure 8: (a) Velocity distribution at the proximal and distal tears, (b) Comparison between the rigid and FSI models: volumetric flow at the proximal (top row) and distal (bottom row) tears. 
(a)

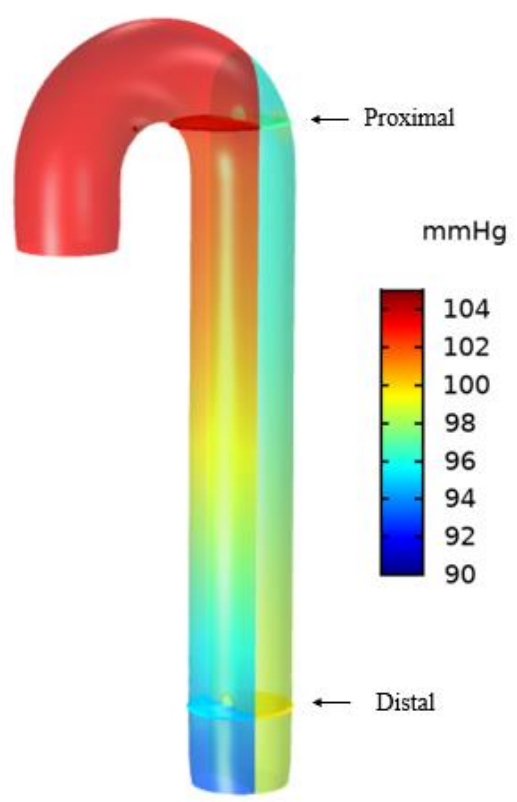

(b)
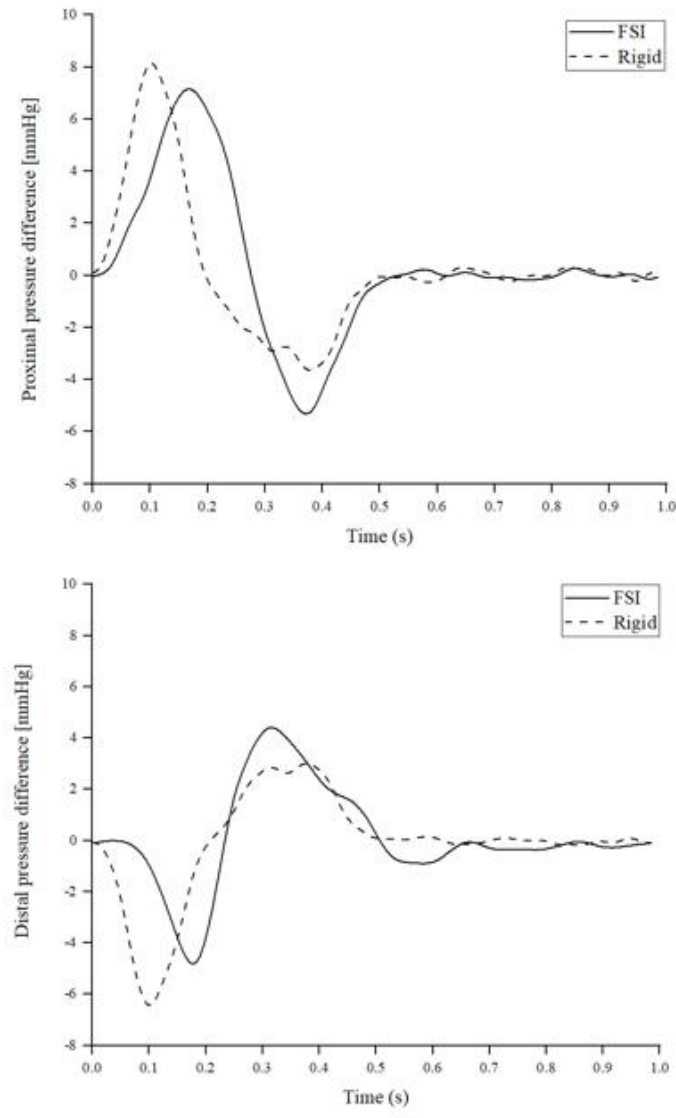

Figure 9: (a) Pressure distribution at 0.16s obtained from FSI model. TL and FL pressure were evaluated in the proximal and distal locations, respectively, as shown, (b) Comparison between the rigid and FSI models: spatial mean pressure difference between the cross-sections of TL and FL $\left(\Delta \mathrm{P}=\mathrm{P}_{\mathrm{TL}}-\mathrm{P}_{\mathrm{FL}}\right)$ at the proximal (top row) and distal (bottom row) locations.
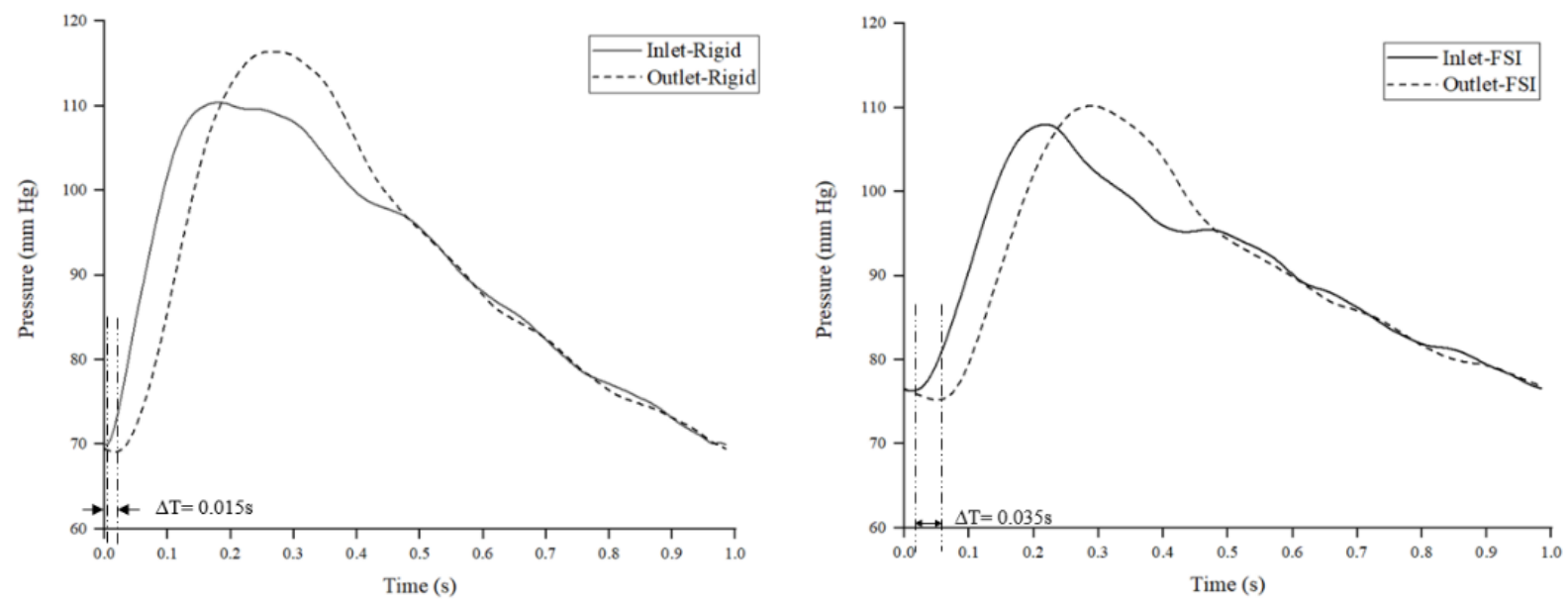

Figure 10: Inlet and outlet pressure waveforms for rigid (left) and FSI (right) models respectively. 


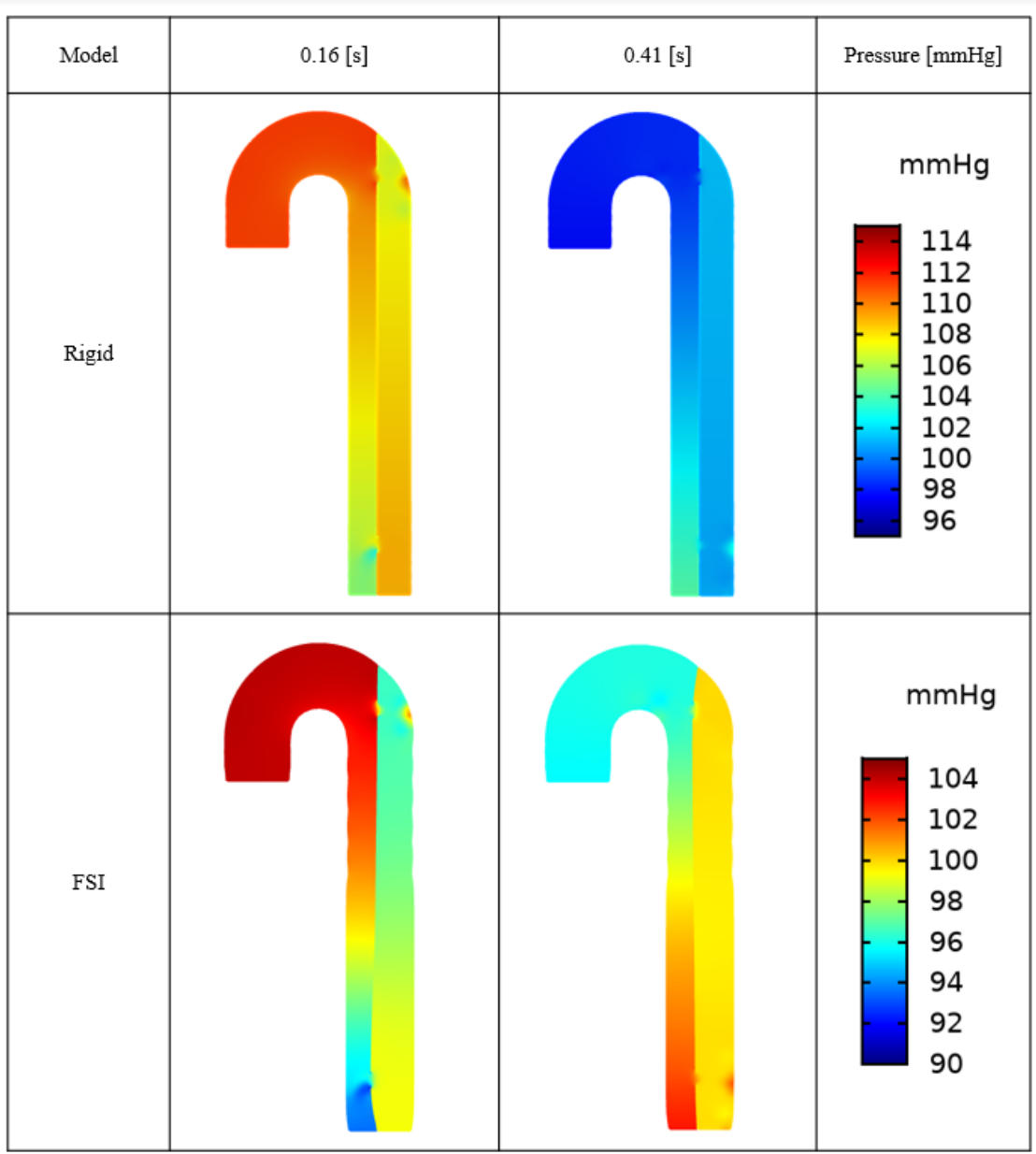

Figure 11: Pressure contour plots for the rigid and FSI models at peak systole $(0.16 \mathrm{~s})$ and early diastole (0.41s). 


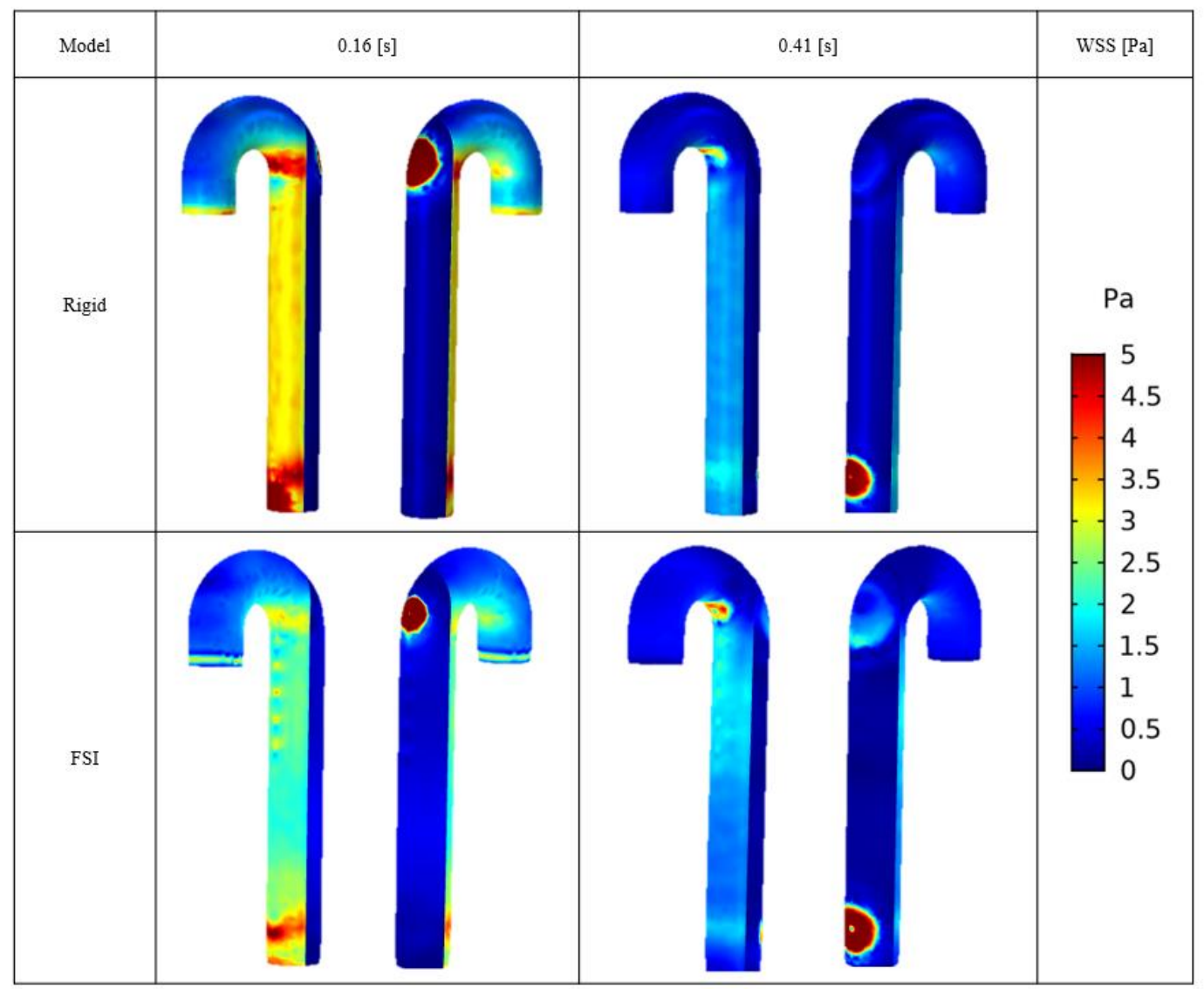

Figure 12: Wall shear stress contours for the rigid and FSI models at peak systole (0.16s) and early diastole $(0.41 \mathrm{~s})$. Each panel contains a right-anterior view (left) and left-posterior view (right).

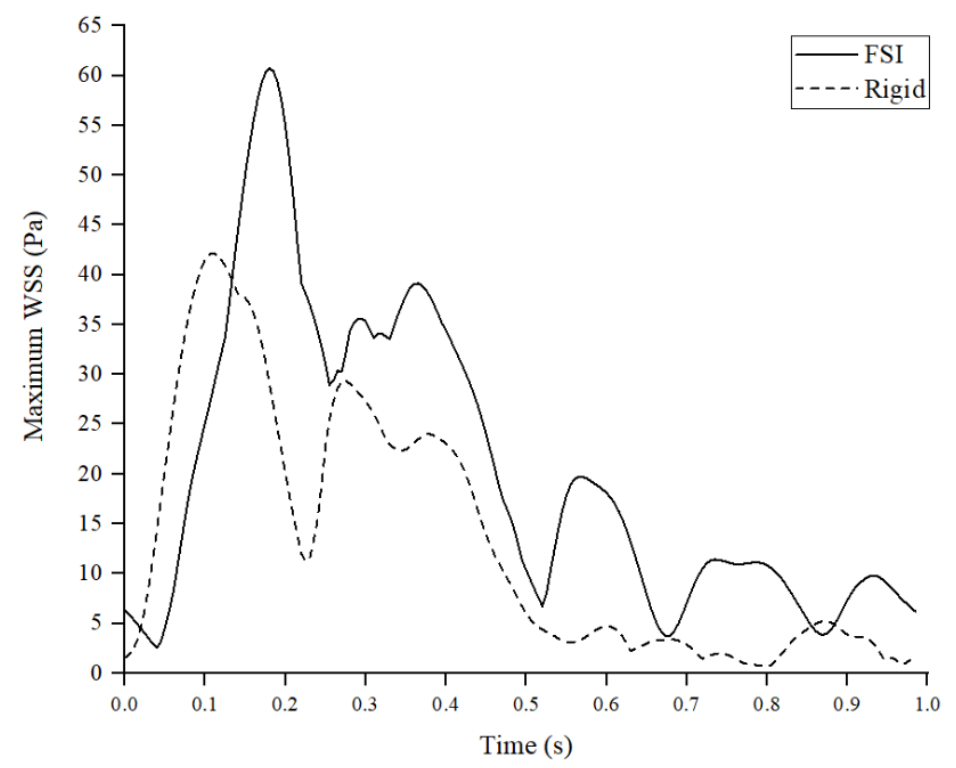

Figure 13: Temporal variations of wall shear stress (WSS) along the cycle, as predicted by FSI and rigid models. 


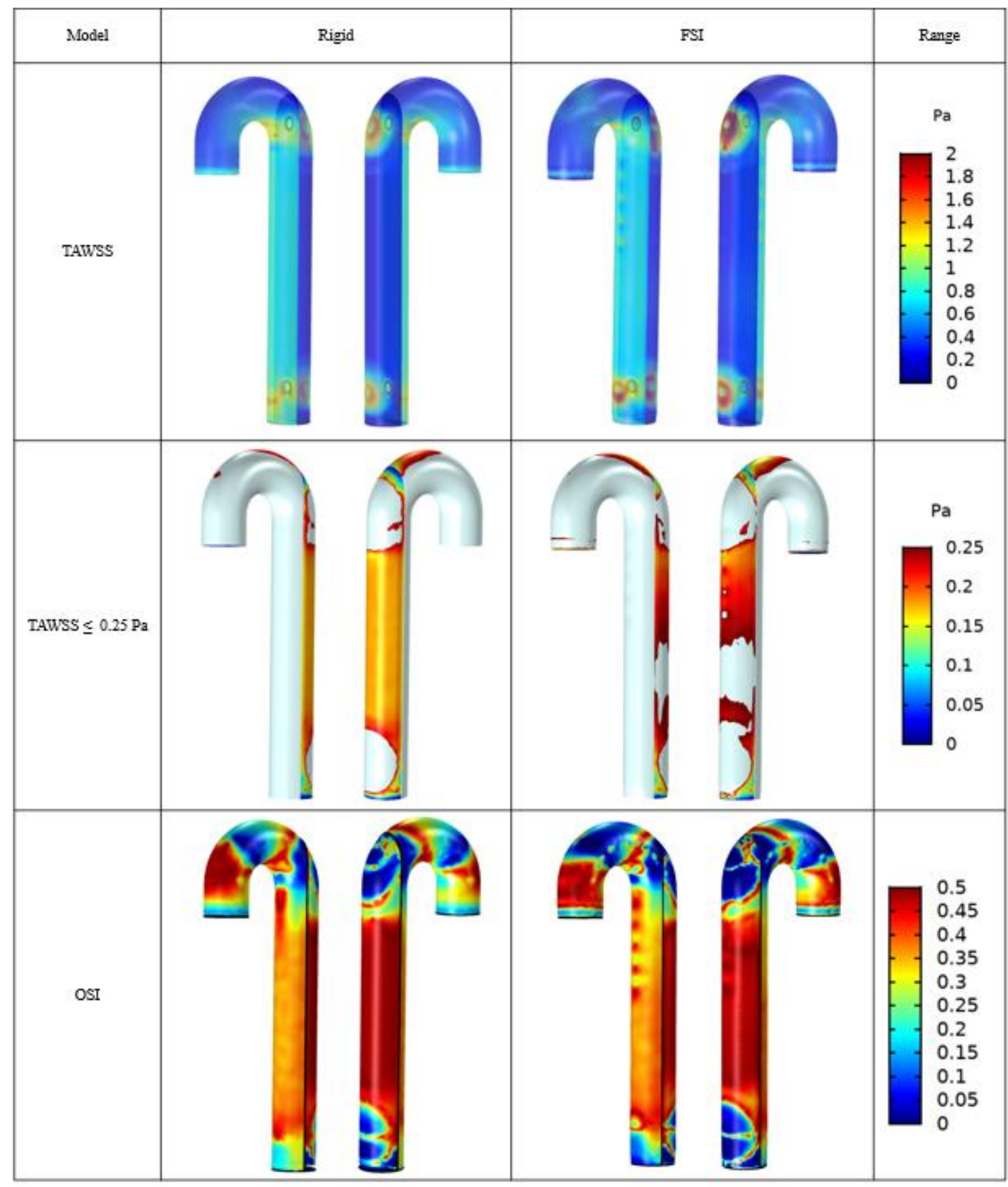

Figure 14: Time-averaged WSS indices: TAWSS and OSI, for rigid and FSI models. 


\begin{tabular}{|c|c|c|}
\hline $0.18[\mathrm{~s}]$ & $0.41[\mathrm{~s}]$ & von Mises stress \\
\hline 0 & $\sum_{1=1}$ & $\left\{\begin{array}{l}1.4 \\
1.2 \\
1 \\
0.80^{5} \\
0.6 \\
0.4 \\
0.2 \\
0\end{array}\right.$ \\
\hline
\end{tabular}

Figure 15: von Mises stress distribution on the intimal flap at $0.18 \mathrm{~s}$ and $0.41 \mathrm{~s}$, respectively. 